the sum of the projections of the momenta of protons on the axis of the shower is $P_{H}=\Sigma \sqrt{E_{H} m_{H}} \cos \alpha=$ $17 \cdot 6 \sim 20$. Assuming that the total momentum of the neutrons has approximately the same value as that of the protons, we obtain the value of $\sim 40$ for all the particles from nucleus. If we calculate the momentum, $P_{N}=\sqrt{E_{N m_{N}}}$ from the value of the energy of the incident particle, we obtain $P_{N} \sim 30$ in the case of $m_{N}=1$. This number is in satisfactory agreement with the value measured from the photographs.

In the second shower there are about fifty tracks and therefore it is reasonable to consider it as the anomalous disintegration of the silver nucleus. Measurement of the particles of the shower shows that $\Sigma E_{H} \sim 150$ and $P_{H}=\sim 70$. In this case the minimum energy of the incident particle is $E_{N} \sim 1,300$ $\mathrm{MeV}$. and $P_{N} \sim 35$ (for $m_{N}=1$ ).

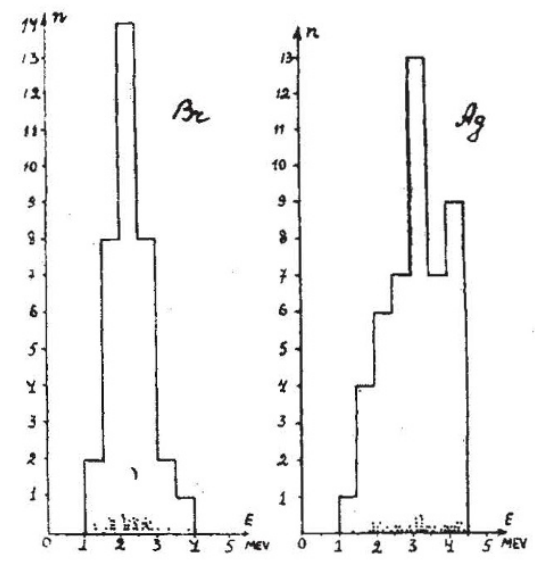

FIG. 3.

It should be noticed that $P_{N}$ is in both cases somewhat less than $P_{H}+P_{n}$.

If the disintegrations were due to photons, electrons or even to mesotrons, the momentum would have quite another order of magnitude. It is interesting to notice that all the particles in the showers are emitted within a cone the cross-section of which is a very eccentric ellipse. For example, in our cases the ratios of the axes of the ellipses are 0.13 and 0.15 , and for the shower described in the previous paper ${ }^{5}$ is $0 \cdot 1$. This eccentricity of disintegrations can be explained by the fact that the collision between the cosmic particles and the nucleus is non-central.

Thus the existence of the showers shows the presence of heavy particles of mass $m \cong 1$ and energy $\sim 10^{\circ} \mathrm{eV}$. in the cosmic radiation at sea-level.

Further details and examples of anomalous disintegration of nuclei will be submitted to the Physical Review.

${ }^{1}$ Shapiro, M., Rev. Mod. Phys., 13, 58 (1941).

2 Myssovsky, L., and Tschishow, P., Z. Phys., 44, 408 (1927). Jdanov, A., J. Phys, et le Rad., 6, 233 (1935).

sdanov, A., Bull. Acad. Sci. URSS., 4, 266 (1940).

- Jdanov, A., C.R. Acad. Sci. URSS., 28, 109 (1940). Pilippov, A. Jdanov, A., and Gurevich, I., C.R. Acad. Sci. URSS., 18, 169 (1938); J. Phys. U.S.S.R., 1, 51 (1939).

s Jdanov, A., Nature, 143, 682 (1939); C.R. Acad. Sci. URSS., 28, 29 (1939).

- Jdanov, A., Perfllov, N., and Deisenroth-Myssowskaya, M., read at the meeting of the Chemical Department of the Academy of Sciences of the U.S.S.R., Feb. 6, 1943, and sent to the Physical Review.

\section{INDIAN FOREST WAR-TIME PRODUCTS}

$\mathrm{W}$ HEN Lord Curzon, Viceroy of India, sanctioned in 1906 the institution of a Forest Research Institute, with headquarters at Dehra Dun, even so wide-visioned a man as he could not have anticipated the great benefits it was to confer on India. Even during the War of 1914-18 the imports into India of what had previously been deemed necessaries of life were curtailed, and forest research at once stepped into the breach and by the close of that War had not only established its position but had outgrown all the buildings, equipment and so forth for which provision was made by 1914 , although it was considered sufficient for the next score of years. A great new building and much additional equipment was sanctioned by 1920 and has long been functioning. During the present War, in some directions the Institute has been able to answer urgent imperative calls of both Army and public. Curiously enough, although the chief branches of forestry were catered for, including utilization, which assumes such an important place in war-time, it was not until comparatively late in its existence that the importance of the minor products of the Indian forests, admittedly a sub-branch of utilization, received due recognition at the Institute - or perhaps at the hands of Government-a special branch being at length formed which has proved of the very highest value, especially in combination with the Chemical Branch, during the present War. Some of this work has already been noted in these columns. Two Indian Forest Leaflets, Nos. 60 and 64, Sylviculture (Forest Research Institute, Dehra Dun, 1944), issued recently, deal with two further products of the Indian forest.

No. 60 is entitled "Short Note of the Beedi Leaf Industry". Beedis are locally made Indian cigarettes with leaf wrappers. As an article of merchandise the industry is believed to have started between 1905 and 1916 in different parts of India, chiefly in Bihar, the Central Provinces, the Eastern States and Patna. The traditional smoke of the Indian is the hookha and chilam. For purely agricultural pursuits the hookha is not an encumbrance, but it is difficult to carry about, and the chilam is a fragile article. With increased industrialism and faster travel by rail and motor-car, the need for a cheap and more portable smoke was met by the cheap foreign cigarette. Supplies of these became difficult to obtain during the War of 1914-18, and the beedi began to become known. The use of leaves of local tree species for making pipes was a common practice of many tribes; it was a short step therefrom to using leaves for preparing cheap cigarettes, and the present War has given a great impetus to this manufacture, expanding industry and the great increase in the Indian Army being two important factors.

The leaves of many indigenous plants are used for wrapping tobacco in, but Diospyros Melanoxylon is the one generally preferred owing to its peculiar flavour, flexibility in texture and resistance to early decay. It occurs in the southern two thirds of India proper from, roughly, an east and west line approximately a hundred miles to the north of Calcutta. Other leaves used are those of Bauhinia racemosa and $B$. vahlii, Butea frondosa, Castanopsis indica and Shorea robusta. The supply of the leaves is eminently a forestry industry, and the best methods of obtaining the maximum crop of leaves, whether 
by pollarding, coppicing or root-suckers, are being closely investigated. The pamphlet deals with the financial and industrial aspects, period of collection of the leaves and grading, drying, still under experiment, storage, packing and transport.

Leaflet No. 64, on "The Growing of Cryptostegia grandiflora as a War-time Emergency Crop", describes another and more important war-time object, namely, the production of rubber. Cryptostegia grandiflora is indigenous to Madagascar and probably to Africa. The plant is described as a scrambler; it grows erect until about $1 \frac{1}{2} \mathrm{ft}$. high and then it climbs and scrambles until after some years it can again stand by itself. It is therefore greatly helped in its early development if it has something to climb on. It was imported into India many years ago as a garden plant for its flowers. It has since run wild in many places, generally in arid or semi-arid climates; for example, Kalka near Delhi, Muttra near Poona, Hyderabad (Sind), etc., with a rainfall of 5-25 in. and elevations up to $1,500 \mathrm{ft}$. In such situations it was noticed that the best development occurred on land subject to local inundations, but it obviously could withstand arid conditions. A survey by the Indian Agricultural Research Institute revealed the fact that it was present in all parts of India in various soils; namely, black, brown, red, laterite, IndoGangetic alluvium, sands, clays, acid and alkaline soils; in all climates without regard to temperature, rainfall, humidity, light, wind and exposure; on river banks and where the subsoil water table is high-an amazing power of adaptation. It is considered probable that a well-drained fertile soil with a gentle slope at about $1,000 \mathrm{ft}$. elevation and a rainfall of $60 \mathrm{in}$. will suit it best, particularly if it can be irrigated during periods of dry weather.

Since the Japanese occupation of Malaya and the Dutch East Indies, which deprived the Allies of some 90 per cent of their supplies of raw rubber, much work has been done on the possibilities of developing additional war-time supplies of vegetable rubber. The Cryptostegia in question has proved a most promising plant, and in the past eighteen months or so experimental work has been carried out and largescale experience gained. Most of the publications on this work have been academic rather than practical. The present pamphlet, it is emphasized, only sets out to give the information at present available, based on a year's practice in planting plantations of the plant for the sole purpose of obtaining the maximum production of rubber in the minimum time, the question of costs not being of primary importance. A better plantation technique will be a matter for the future should this type of cultivation be found remunerative after the War. The seed is sown in nurseries and the seedlings put out at the outbreak of the rains when about two months old. They are planted in lines or double lines about $6 \mathrm{ft}$. apart to allow room for the tapping operations to be undertaken. Each row has a simple form of fence $4 \mathrm{ft}$. $6 \mathrm{in}$. high on which the plants can climb. Since the object is to obtain maximum results in the shortest time, dense planting is necessary. "Tapping," it is said, "has of necessity to be of a few shoots per bush; therefore we have to grow these shoots at such a height and by such an arrangement that the labour can tap as many shoots as possible in the smallest area with the minimum of trouble."

The pamphlet gives full details of all the operations necessary to form a plantation and to exploit it, but emphasizes the fact that the methods at present employed are the results of, and therefore to some extent due to, the fact that during the past year it has been a 'rush-job'. From the descriptions given of the work it seems to be very satisfactory, and to reflect great credit on the careful research work which has enabled it to be carried out at so critical a time for the Allies' rubber resources.

\section{FLINT KNAPPING}

$T^{0}$ O fashion a flint implement both knowledge of the tricks of the trade and skill in execution are required. Watching the flint knappers at Brandon can teach the student many a 'wrinkle', but any attempt to do likewise soon demonstrates the overriding importance of long and patient practice. The Pitt Rivers Museum authorities at Oxford have recently issued their first Occasional Paper on Technology, and it is entitled "The Manufacture of a Flint Arrowhead by Quartzite Hammer-stone"*. The author is Sir Francis Knowles and the work is plentifully illustrated. One can only regret that the writer had not the chance to collaborate in a more extensive work with M. Contier who, though he has, so far as I know, published nothing, is perhaps the most skilful maker of flint tools in existence.

M. Contier is, or was, an ornamental stonemason with a workshop in the outskirts of Paris; but he was also a pupil of Breuil in the typology of flint implements, and the combination has been very fruitful. It was he who showed that the singlefaceted, highly inclined striking platform of the socalled Clacton technique involved the swinging of a nucleus against a stone anvil; while the right-angled platform of the Levallois implements could be produced by vertical blows on the nucleus with a hammer-stone. Again, it was Contier who discovered the possibilities of the 'wood technique' : the striking of the core, held in the hand, with a baton of wood instead of with a hammer-stone, whereby flaking similar to that long recognized as characteristic of Acheulean tools can be produced. Actually, the use of the softer hammer partially resolves the phenomenon of percussion produced by a stone hammer into that of pressure. A dictum of Contier's used to run-the Chellean technique is that of the anvil, but Acheulean man held the flint core in his hand and hit it with a wooden baton. He also, like Dr. Leakey, had definite views as to how the various types of burins were made.

But Contier was essentially a craftsman. Sir Francis Knowles, though with a limited, definite objective, has given us the written word upon this subject of technique. $\mathrm{He}$ is concerned only with the manufacture of arrowheads, using a quartzite hammer-stone, not an iron hammer as do the knappers of Brandon. His paper is the book of words for doing this. He tells us how to choose the materials, how to hold and hit them, how to 'turn the edge' of the flake, etc. His instructions are indeed what a cook would call the 'recepe' for the production of a complicated and beautiful piece of craftsmanship. Very definitely papers of this kind have value; still far too little is known about the material flint and the various ways in which it can be fractured. Incidentally, anyone who has tried his hand at it will know the difficulty of describing in words

- Pitt Rivers Museum, University of Oxford. Occasional Papers on Technology, 1: The Manufacture of a Flint Arrow-head by Quartz-
ite Hammer-stone. By Sir Francis Knowles. Pp. $38+6$ plates. 58 . 